\title{
Urgences
}

\section{Voilà pour la...}

\section{Renaud Longchamps}

Numéro 15, octobre 1986

Épigraphiques

URI : https://id.erudit.org/iderudit/025328ar

DOI : https://doi.org/10.7202/025328ar

Aller au sommaire du numéro

Éditeur(s)

Urgences

\section{ISSN}

0226-9554 (imprimé)

1927-3924 (numérique)

Découvrir la revue

Citer ce document

Longchamps, R. (1986). Voilà pour la... Urgences, (15), 65-66. https://doi.org/10.7202/025328ar

Ce document est protégé par la loi sur le droit d'auteur. L'utilisation des services d'Érudit (y compris la reproduction) est assujettie à sa politique d'utilisation que vous pouvez consulter en ligne.

https://apropos.erudit.org/fr/usagers/politique-dutilisation/
Cet article est diffusé et préservé par Érudit.

Érudit est un consortium interuniversitaire sans but lucratif composé de l'Université de Montréal, l'Université Laval et l'Université du Québec à Montréal. Il a pour mission la promotion et la valorisation de la recherche. https://www.erudit.org/fr/ 


\section{Renaud Longchamps}

On ne s'évade pas de l'espèce.

Henri Michaux: d'un livre non déterminable actuellement..

Voilà pour la matière, faux mouvement, de laquelle viendra l'autre animation, l'autre programme. Faux. Maintenant je sais: le génome radote, rafistole, raffole de redondance et de matériels désuets, désormais muets sur la chaîne d'assemblage des protéines, protéines qui ne reconnaissent pas l'indifférence sérielle, ni la superbe insignifiance dans la signification à tout prix. Ainsi perdu dans son propre filet, il n'a rien à dire. Toute la matière condamnée à se tenir au garde-à-vous dans l'attente du choix, de l'événement. Elle pourrit sur place, la pauvre, dans les attitudes et les milliards d'années de ventres faillis. Centaines, milliers de voies de garage, huileuses, défoncées, herbeuses, qui exhalent la momie, le moisi, le poisson, le reptile, le mammifère!

Que faites-vous dans la vie? Rien, J'attends. Des hommes homogènes aux petits pouvoirs pourris. Des femmes indigentes aux désirs inassouvis de petits pouvoirs pourris. Elle s'agite, la vie! Elle s'agite, grave et définitive, bricoleuse à ses heures, dans l'horreur de la mort, fin de programme et de partie à perpétuer comme si.

Comme si l'espèce n'avait pas assez de se savoir condamnée. Comme si l'espèce ignorait que sa moyenne de vie ne dépasse guère les cinq millions d'années et que c'est assez de toutes ces traites à tirer sur l'usure. Comme si le corps ne sentait pas que sa mort est aussi la mort de l'espèce, puisque le temps parle et passe, passe et parle à travers d'autres espèces que nous bafouons, dont nous abuserons certainement, sur cette terre comme au ciel.

Depuis Cro-Magnon, l'espèce n'évolue plus. Sauf dans le dédale de son génome, fourre-tout magnifique.

On ne s'évade pas. Trop de silences dans l'ADN. "Je ne sais plus parler". L'arête d'acides aminés s'arrête là, dans la voix. Hommes, femmes, avant la justice, avant le savoir et ce qui reste d'amour, même usage! même usure! Est-ce privilège que connaître sa finalité avant l'effritement?

On ne s'évade pas. Trop de parenthèses à l'intérieur desquelles vous écrivez, vous vous agitez, vous croyez reconnaître la nuit dans le jour, 
vous lisez sur le papyrus biologique que vous participez parfois, et que parfois le singulier se démarque du nivellement pratiqué dans les milliards d'années. Quel singulier? Le singulier de quelques livres de graisse, de quelques territoires, de quelques lignes que bien des générations suivantes réécriront, dans l'ignorance du déjà-dit, cent fois remâche, mille fois recraché. La vie, quoi, infiniment vulgaire, fumiste et plagiaire pour notre malheur... pour notre grand malheur!

Tous aux abris! La vie aboie. Elle mord au talon, pendant l'extase. 